\title{
Modelling the Estimation Process of Greenhouse Gas Emission in the Construction of Buildings
}

\author{
$\mathrm{Yi}, \mathrm{Kyoo}^{-} \mathrm{Jin}^{*}$ \\ Department of Safety Engineering, Hankyong National University, Anseong, Gyeonggi-do, 456-749, Korea
}

\begin{abstract}
The annual expenditure on diesel oil and heavy oil in the construction sector is the second largest among all industrial sectors. To meet the government's greenhouse gas reduction targets, the construction sector has until 2020 to cut its emissions by $7.1 \%$. Unlike other high-tech industrial sectors, the construction sector has a fairly limited scope for technological improvements, which hampers its capacity to achieve the reduction target. To reduce emissions, it is necessary to establish an energy and emissions strategy at the project planning stage, and energy use and the resulting emissions must be estimated. This research aims to establish an estimation methodology for greenhouse gas emissions at the planning stage of construction projects. To estimate the project-related emissions, this research indentified the relationship among the types of emissions in a cross-sectional matrix form, and then provided a set of calculation methods for total project related emissions.
\end{abstract}

Keywords : green construction, building construction, greenhouse gas, construction management, energy consumption

\section{Introduction}

According to NOAA(National Oceanic and Atmospheric Administration) and NASA(National Aeronautics and Space Administration), the average temperature of the earth' $\mathrm{s}$ surface has risen by $0.7 \sim 0.8^{\circ} \mathrm{C}$ during the last 100 years. This phenomenon is considered to be caused by the continuous increase of greenhouse gas emissions, and if it continues, it is likely that the average earth surface temperature will rise to $1.8 \sim 4.0^{\circ} \mathrm{C}$ higher than year 1990 level by the end of the 21st century[1].

In developed countries, the construction sector

Received : October 27, 2011

Revision received : December 2, 2011

Accepted : February 7, 2012

* Corresponding author: Yi, Kyoo-Jin

[Tel: 82-31-670-5285, E-mail: helden@hknu.ac.kr]

(C)2012 The Korea Institute of Building Construction, All rights reserved. represents $40 \%$ of total energy consumption and $36 \%$ of carbon dioxide emission, figures that are related not only to the on-site construction activities but also to material manufacturing for the construction process. In Western Europe, $8 \sim 18 \%$ of all carbon dioxide emissions are associated with the manufacturing of construction materials, including transportation and assembly. Of the construction materials, production and transportation of concrete and steel share the largest portion of total emissions[2].

The Korean government has announced a greenhouse gas reduction plan, targeting a 30\% reduction by 2020, and the construction sector is to cut $7.1 \%$. Compared to other industrial sectors, this target is relatively modest, but the construction sector has limits when it comes to its capacity for energy saving and emission reduction. Unlike other high-tech industrial sectors, the construction sector is fairly restricted in terms of its capacity to 
achieve technological improvements, without which a reduction in emissions is hardly achievable.

According to Korean Statistical Information Service (KOSIS), annual spending on diesel oil and heavy oil in the construction sector is the secondlargest among all industrial sectors, and kerosene and petrol spending is the third-largest. Moreover, annual spending in the construction sector has been increasing along with the mining and chemical industry, while it has been decreasing in other industrial sectors.

Energy consumption and greenhouse gas emission occurs in every stage of the construction process, including the gathering of raw materials, materials and equipment manufacturing, materials and equipment transportation, on-site assembly, demolition, and disposal of wastes. To reduce emissions, it is necessary to establish an energy and emissions strategy at the project planning stage. In addition, energy use and the resulting emissions must be estimated in order to follow the established strategy.

Due to the inherent characteristics of the construction industry, it is not easy to estimate greenhouse gas emissions in construction projects. For example, there are many aspects of high uncertainty in identifying and assessing the factors in construction sites that affect emissions[3]. In addition, Project management on a construction site is typically carried out based on time, cost, and quality. Although environmental factors have been emphasised recently in most industrial sectors, it is not easy to incorporate environmental factors into construction project management[4].

There has been a great deal of research work dealing with construction-related emission problems. However, most has focused on emissions related to material production before the construction stage or operating facilities after the construction stage, and few have targeted emissions related to the construction stage.

Therefore, this research aims to establish a methodology for the estimation of greenhouse gas emissions at the planning stage of a construction project. The specific objectives are to identify the factors that affect greenhouse gas emission and energy use on a construction site, and to provide a procedure for the estimation of emissions on construction sites.

To estimate energy consumption and greenhouse gas emissions in construction projects, it must be understood that emissions occur throughout the whole process of the life cycle, including material manufacturing and transportation, worker and equipment transportation, on-site assembly, maintenance activities, demolition, and disposal of waste material. This research limits its scope to the factors directly related to on-site construction activities, such as material transportation and its on-site assembly, worker transportation, and equipment transportation. In addition, this research provides a method of estimation for general situations of construction projects, and leaves methods of estimation for individual and specific activities for further research.

\section{Previous Studies}

According to EMAS (The Eco-Management and Audit Scheme)[5], environmental aspects associated with the construction process include (1) emissions to air; (2) releases to water; (3) avoidance, recycling, reuse, transportation and disposal of solid and other wastes, particularly hazardous wastes, (4) use and contamination of land, (5) use of natural resources and raw materials (including energy), (6) local issues (noise, vibration, odour, dust, visual appearance, etc.), (7) transport issues, (8) risks of environmental accidents and impacts 
arising, or likely to arise, as consequences of incidents, accidents and potential emergency situations, and (9) effects on biodiversity. Of these aspects, emission to the air is considered as the direct and indirect cause of global warming, and thus worldwide efforts to achieve reductions in this area are underway.

Although the embodied energy and greenhouse gas emissions associated with construction are generally considered to be relatively small compared to those required after the completion of buildings (such as for the heating, cooling, and operation of buildings), a significant amount of energy is consumed in construction work every year. European and US figures[6], for example, show the construction portion to be about $7-10 \%$ of total embodied energy. The relative significance of greenhouse gas emissions for that is unknown.

Yan[7] and Seo[8] suggested a system boundary of greenhouse gas emissions in the construction of buildings as shown in Figure 1.

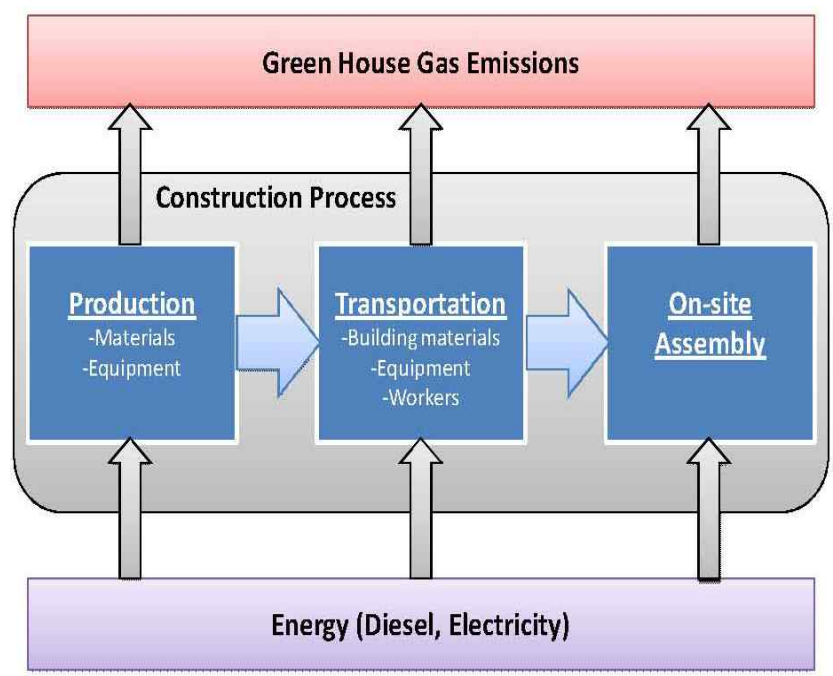

Figure 1. Greenhouse gas emissions in the construction process[8]

Greenhouse gas emissions in the construction sector mostly result from fuel consumption to operate construction equipment and from electricity consumption to provide power to construction tools and offices. Off-road diesel engines used by construction companies feature in a wide variety of equipment, such as loaders, dozers, excavators, graders, and other specialized equipment[9]. To reduce emissions, the US Environmental Protection Agency[10] suggested reduced idling, proper equipment maintenance, driver training, using properly sized equipment, replacing older, fuelefficient equipment with newer models, using lowcarbon fuels, and improving employee commuting method. Among these reduction methods, equipment and transportation related features are found to be the major sources of emission.

Lindgren[11] emphasised that a considerable amount of emissions occurs while operating on-site equipment and transporting materials, and in both cases these are related to equipment. Emissions increases in situations such as an abrupt change in engine load and sudden acceleration are critical factors that affect the amount of emission, and are more common circumstances in the operation of construction equipment than in the operation of a passenger vehicle.

Cole[12] estimated greenhouse gas emission and energy use on construction sites. Cole categorised the aspects of greenhouse gas emission and energy use by the construction industry into three processes - worker and equipment transportation, material transportation, and on-site assembly - and examined energy uses and emissions of construction materials such as wood, concrete, and steel for each process. As shown in Figures 2 and 3, in the case of concrete, for example, it was found that a similar amount of greenhouse gas was emitted at each process, as the ratio is approximately 36:32:31 (On-site equipment use: Equipment \& Material Transportation: Worker Transportation). 


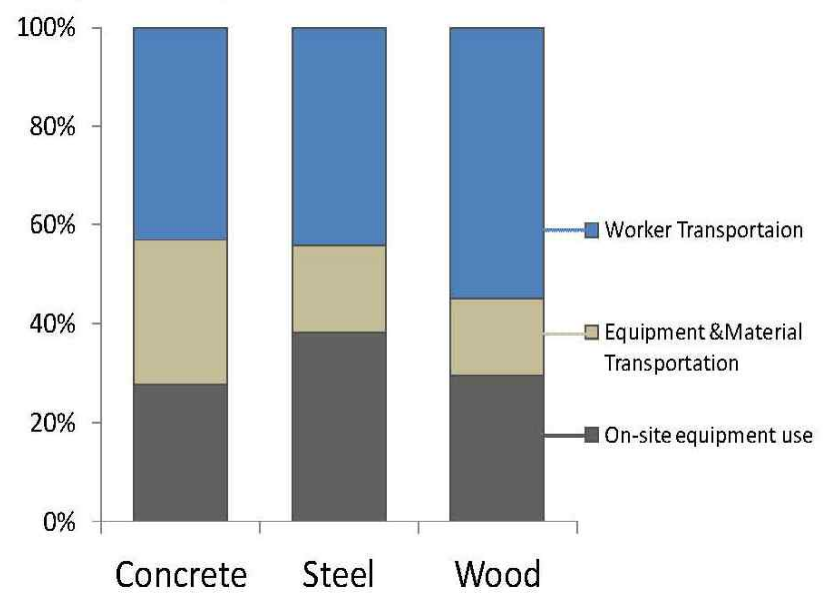

Figure 2. Average construction energy for wood, steel, and concrete assemblies[12]

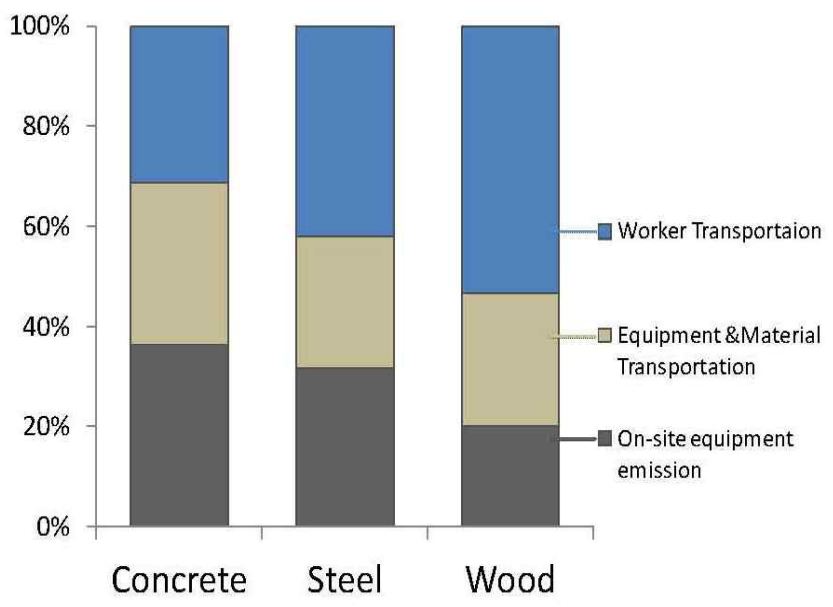

Figure 3. Average construction greenhouse gas emissions for wood, steel, and concrete assemblies[12]

Cole also compared the energy use and greenhouse gas emission from the materials which are selected during the construction process. Embodied energy was defined as the direct and indirect energy used to manufacture, transport, and install building products. In this definition, direct energy refers to the energy consumed in the construction of buildings representing the final transportation and installation of a component or assembly, while indirect energy, sharing the largest portion of embodied energy, represents the energy consumed in the production of building materials and their associated transportation. It includes all the energy used for the production of a component, and excludes the energy used for its transportation and installation on-site.

While Cole's study examined worker transportation, equipment and material transportation, and on-site equipment use in order to estimate energy use and emission by the construction sector, a KICT (Korea Institute of Construction Technology) report[13] explained energy use as the sum of mechanical equipment use, transportation equipment use, office use, and other facilities use, which excluded worker transportation use.

Although previous researchers have taken many approaches, all have viewed the construction project as whole, rather than as a combined process of activities.

\section{Life Cycle Assessment and Research Scope}

LCA (Life Cycle Assessment) is a method of comparing the serviceability and economy of alternatives. When LCA is applied to building construction, it encompasses the analysis and assessment of the environmental influence of the building' s components, elements, and facilities throughout the life cycle of a building, including the construction, operation, and demolition processes.

The analysis of the total environmental effect of a building must include (1) the environmental influences of the energy required for transportation and assembly at the construction phase; (2) the replacement cycles of the various building components at the maintenance phase; (3) waste disposal at the construction and demolition phase; (4) the environmental factors occurring during the manufacturing of building materials for the construction of a building.

As this research deals only with factors directly 
related to on-site construction activities such as transportation and assembly at the construction phase, the manufacturing, maintenance, and demolition phases will not be included.

There are direct and indirect emissions in the construction sector. Direct emission involves the emissions related to the work process occurring in construction sites, and it is typically associated with the operation of equipment for excavation and hauling. Indirect emission occurs during the acquisition of raw materials, the manufacturing of the materials needed for the construction, and design and inspection[14]. This study excludes indirect emission from the research scope.

\section{Transportation Emission and On Site Emission}

On-site energy use includes all the direct energies required for the installation and assembly of building components, the placing and curing of concrete, etc. According to Cole[12], as indicated in Figure 3, the on-site energy use rarely exceeds onethird of the total energy required for the construction of a building. The remaining portion constitutes the energies required for the transportation of materials, components, and facilities as well as the transportation of workers. In this case, petrol and diesel usage for worker transportation can be assumed, as well as diesel for material and equipment transportation and diesel and electricity for on-site equipment use.

\section{Estimation of Energy Use}

In estimating the amount of energy use, transportation-related energy can be estimated based on the quantity estimate data, such as materials and labour required for each work process. The time and amount of material to be transported can be estimated based on the quantity estimates and work schedule. Quantity estimates contain information about the amount of materials required for each work process, and work schedule explains when these materials must be transported. The time and amount of equipment transportation can be estimated in similar ways. The transportation of fresh concrete, for instance, is related to the distance between the batching plant and the construction site. As fresh concrete must be delivered within the setting time, its travel distance is assumed to be less than one or two hours' distance. Since more energy is required when a vehicle is travelling to the site (loaded) than when it is returning from the site (empty), these must be separately estimated.

With respect to equipment and machinery transportation, the amount of energy required for transportation needs to be estimated according to the type of equipment and machinery to be transported, which again depends on the project type and the characteristics of the work process. Large-scale excavation work, for example, needs a relatively larger amount of equipment than labour force, while small-scale building construction tends to use more manual labour. Equipment such as forklifts and tower-cranes are operated throughout most of work processes and tend to consume relatively more energy for on-site assembly work than for transportation. On the other hand, equipment such as truck cranes and concrete mixer trucks tend to consume relatively more energy for travelling than for on-site work. In such cases, the frequency with which the equipment must travel can be estimated by dividing the work quantity of each by its capacity. By multiplying the travelling frequencies by the travelling distance, total travelling distance can be estimated, and its energy requirement can also be estimated, accordingly. 
Material transportation can be estimated according to the travelling load, distance, and frequency. Worker transportation is more complicated, as there are various types of transportation methods. As travelling distance and means of transportation affects the amount of energy, and there is a difference in load between transporting and returning, separate values or average values can be applied for the estimation of transportation use. In order to estimate average values, site location and traffic situation must be considered, as those values significantly affect the result.

Since construction projects have some labour intensive characteristics, a large amount of energy is required for worker transportation, which means that worker transportation is directly related to emissions in the neighbouring area. Worker transportation occurs throughout the construction period, and the amount of worker transportation can be estimated based on the resource allocation schedule.

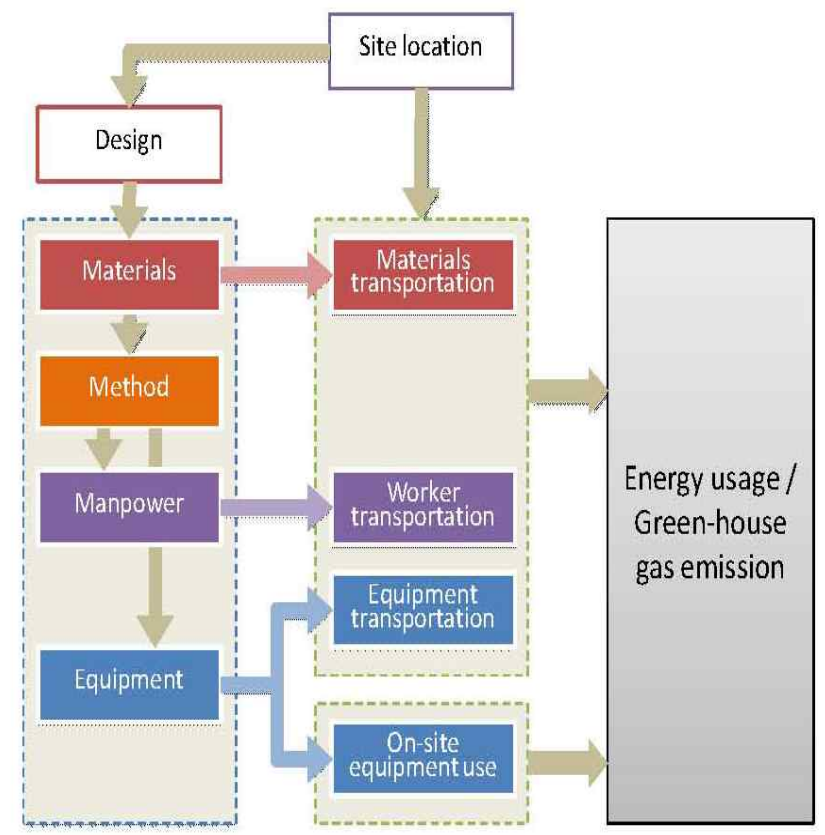

Figure 4 . The effect of construction factors on greenhouse gas emission and energy use

\section{Modelling Emission Process}

The amount of greenhouse gas emission due to the energy use from construction sites varies according to the type of structural assembly, construction method, material, etc. Figure 4 shows the effect of various factors of construction sites, such as materials, methods, manpower, and equipment, on the greenhouse gas emission and energy use.

Site location affects design and transportation distance. Designers determine the materials to be used, which affects the amount of material transportation. Before assembling the materials, the assembly method, equipment, and manpower must be decided, which affects the amount of worker and equipment transportation. Figure 5 is the stock and flow diagram showing the process of energy burning and emission and the effect of various factors on these.

Transportation use and on-site use are the two main types of energy use and greenhouse gas emission from construction sites. If we look at these two types of energy use and greenhouse gas emission in relation to workers, equipment and materials, and work processes, it can be summarised as shown in Figure 6.

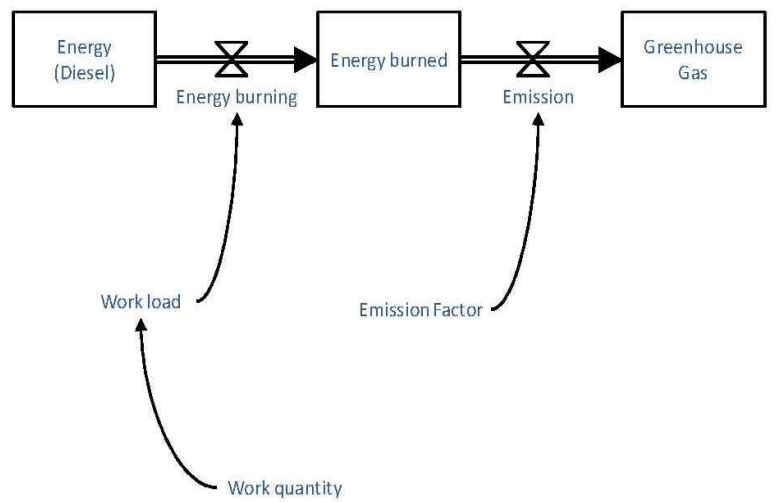

Figure 5. Stock and flow diagram showing the effect of various factors on greenhouse gas emission in construction projects 


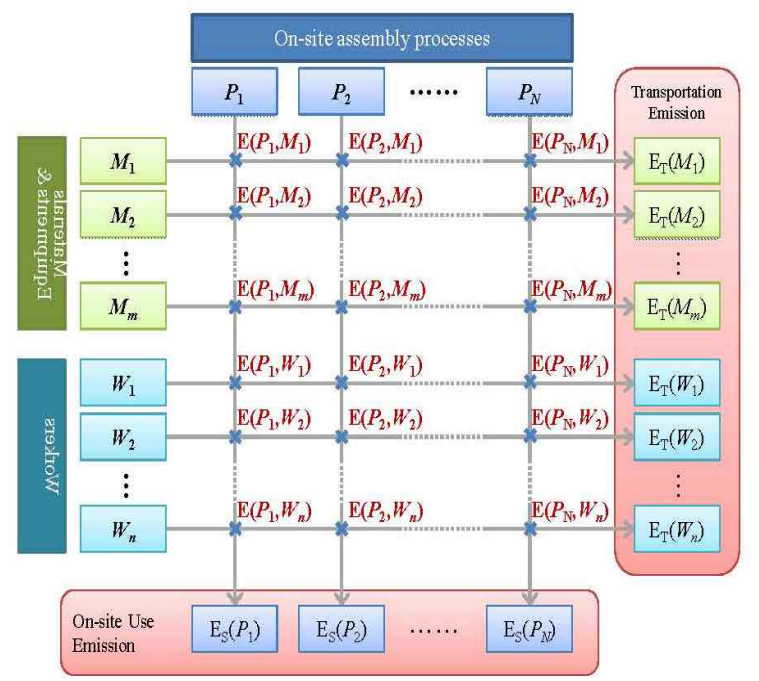

Figure 6. Greenhouse gas emission occurrence points in relation to workers, equipment and materials, and processes

Every intersection of the axis is an estimation point where emission can occur. For instance, at the intersection point of the process $P_{i}$ and the material $M_{j}$, two types of emission can occur - transportation emission $\mathrm{E}_{\mathrm{T}}\left(P_{i}, M_{j}\right)$ and on-site use emission $\mathrm{E}_{\mathrm{S}}\left(P_{i}, M_{j}\right)$; likewise, for the process $P_{i}$ and the worker $W_{k}, \mathrm{E}_{\mathrm{T}}\left(P_{\mathrm{i}}, W_{k}\right)$ and $\mathrm{E}_{\mathrm{S}}\left(P_{\mathrm{i}}, W_{k}\right)$ can occur. By adding the two types of emissions, the total emission amount can be estimated.

$$
\mathrm{E}=\mathrm{E}_{\mathrm{T}}+\mathrm{E}_{\mathrm{S}}
$$

Production-related emissions (equipment and materials) include emissions required for the production, maintenance, and recycling of construction machines, tools, equipment, and materials,

$$
\begin{gathered}
E_{\text {production }}=E_{P}\left(M_{1}\right)+E_{P}\left(M_{2}\right)+\cdots+E_{P}\left(M_{m}\right) \\
=\sum_{k=1}^{m} E_{P}\left(M_{k}\right)
\end{gathered}
$$

where $E_{P}$ is the production-related emission and $M_{1}, M_{2}, \ldots, M_{m}, k^{\text {th }}$ materials and equipment.

On-site use emission:

$$
\begin{gathered}
E_{\text {on-site use }}=E_{S}\left(P_{1}\right)+E_{S}\left(P_{2}\right)+\cdots+E_{S}\left(P_{N}\right) \\
=\sum_{i=1}^{N} E_{S}\left(P_{i}\right)
\end{gathered}
$$

where $E_{s}$ is the on-site use emission and $P_{1}, P_{2}, \ldots, P_{N}, I^{\text {th }}$ assembly processes.

Equipment and material transportation:

$$
\begin{aligned}
E_{\text {transport }(E \& M)}= & E_{T}\left(M_{1}\right)+E_{T}\left(M_{2}\right)+\cdots+E_{T}\left(M_{m}\right) \\
& =\sum_{k=1}^{m} E_{T}\left(M_{k}\right)
\end{aligned}
$$

where $E_{T}$ is the transportation emission and $M_{1}, M_{2}, \ldots, M_{m}, k^{\text {th }}$ materials and equipments.

Worker transportation emission:

$$
\begin{aligned}
E_{\text {transport(worker) }} & =E_{T}\left(W_{1}\right)+E_{T}\left(W_{2}\right)+\cdots+E_{T}\left(W_{n}\right) \\
& =\sum_{j=1}^{n} E_{T}\left(W_{j}\right)
\end{aligned}
$$

where $E_{T}$ is the transportation emission and $W_{1}, W_{2}, \ldots, W_{N}, J^{\text {th }}$ trades of workers.

Total projectrelated emission:

$$
\begin{gathered}
\mathrm{E}_{\mathrm{tot}}=E_{\text {production }}+E_{\text {on-site use }}+E_{\text {transport }(E \& M)}+E_{\text {transport }(\text { worker })} \\
=\sum_{k=1}^{m} E_{P}\left(M_{k}\right)+\sum_{i=1}^{N} E_{S}\left(P_{i}\right)+\sum_{k=1}^{m} E_{T}\left(M_{k}\right) \\
+\sum_{i=1}^{n} E_{T}\left(W_{j}\right)
\end{gathered}
$$

Emissions for individual activities can be estimated according to the guidelines provided by previous researchers, such as IPCC guidelines[15] and Korea Institute of Construction Technology report[13]. IPCC guidelines provide emissions estimation methods for mobile and stationery combustions. In order to obtain the data required to estimate the on-site emissions as displayed in Figure 6, detailed quantity estimates and work schedule is required. For instance, the amount of energy required for a particular work process can be estimated by multiplying its work quantity by its 
unit energy requirement. With regard to the on-site use data for equipments and materials, energy requirement can be derived from productivity, engine size, transportation load, etc. On construction sites, there is various equipment that directly or indirectly emits greenhouse gas on-site. Direct emission equipment includes most dieselpowered equipment, such as dozers, loaders, backhoes, etc. while indirect emission equipment mostly uses electric powers. Indirect emissions can be estimated by oil equivalent conversion factors, and direct emissions can be estimated using emission factors specific to each source of power. For the estimation of electricity powered equipment, oil equivalent conversion factors and carbon footprint can be used according to the power generation systems. For instance, coal burning power systems have the largest carbon footprint of all the electricity generation systems analysed here. The average carbon footprint of oil-fired electricity generation plants is $650 \mathrm{gCO} 2 \mathrm{eq} / \mathrm{kWh}$. Current gas powered electricity generation has a carbon footprint around half that of coal $\left(500 \mathrm{gCO}_{2} \mathrm{eq} / \mathrm{kWh}\right)$.

\section{Conclusion}

This study was conducted in order to identify the range and types of greenhouse gas emission in building construction projects. Greenhouse gas emission can be divided into production-related emissions and projectrelated emissions. Productionrelated emission includes the manufacturing of building materials, equipment, tools, etc. while projectrelated emissions consist of on-site use emissions, worker transportation emissions, and equipment and material transportation emissions. Emissions related to the disposal of construction waste can also be included in on-site assembly, which in this research are assumed as estimated independently.

To estimate the projectrelated emissions, this research indentified the relationship among the three emission types in a cross sectional matrix form, and then provided a calculation method for total project related emissions. The estimation method presented in this research will be used for the following purposes,

First, this method can be used to generate a more feasible estimation of energy use and greenhouse gas emission by incorporating work processes and energy use for transportation and on-site assembly, and the results can be used for more energyefficient project management.

Furthermore, it can be used to predict and compare the greenhouse gas emission of alternative construction plans, and to adjust plans to select the more energy-efficient and less greenhouse gas emitting project plan for on-site assembly.

In addition, it can be used to provide comprehensive evidence of greenhouse gas emission to the client and to the local authority.

As there are high uncertainties on construction sites, an accurate estimation of emissions is not always possible. The estimation methods provided in this research will be more useful if they are combined with probability theories. Further research is needed to implement models that explain uncertainty and provide a range of deviation for greenhouse gas estimation.

\section{Acknowledgement}

This work was supported by a research grant from the Academic Research Foundation of Hankyong National University for a scholarly exchange program in 2011 


\section{References}

1. Truitt P. Potential for Reducing Greenhouse Gas Emissions in the Construction Sector. Washington, DC: US Environmental Protection Agency; 2009. p. 1.

2. Nassen J. Direct and Indirect Energy Use and Carbon Emissions in the Production Phase of Buildings: An InputOutput Analysis. Energy. 2007 May;32(5):1593-602.

3. Gangolells M. Assessing Concerns of Interested Parties when Predicting the Significance of Environmental Impacts Related to the Construction Process of Residential Buildings. Building and Environment. 2011 Nov;46(11):1023-37.

4. Gangolells M, Casals M, Casso S, Forcada N, Roca X, Fuertes A. a Methodology for Predicting the Severity of Environmental Impacts Related to the Construction Process of Residential Buildings. Building and Environment. 2009 Mar;44(3):558-71.

5. European Parliament and the Council of the European Union. Regulation (EC) No. 761/2001 of the European Parliament and of the Council allowing voluntary participation by organizations in a Community eco-management and audit scheme (EMAS). Official Journal of the European Communities L 114 [Internet]. 2001 Apr [cited 2012 May];L114:1-29. Available from: http://europa.eu.int/eurlex/pri/en/oj/dat/2001/1_114/1_11420 010424en00010029.pdf

6. Cole RJ, Rousseau D. Environmental Auditing for Buildings Construction. Energy and Air Pollution Indices for Building Materials. Buildings and Environment. 1992 Jan;27(1):23-30.

7. Yan H, Greenhouse Gas Emissions in Building Construction: A Case Study of One Peking in Hong Kong. Building and Environment. 2010 Apr;45(4):949-55.

8. Seo S, Hwa ng Y. Estimation of $\mathrm{CO}_{2}$ Emissions in Life Cycle of Residential Buildings. Journal of Construction Engineering and Management. 2001 May;127(5):414-8.

9. Truitt P. Quantifying Greenhouse Gas Emissions from Key Industrial Sectors in the United States. Washington, DC: US Environmental Protection Agency; 2008. Chapter 5, Construction; p. 1.

10. Truitt P. Potential for Reducing Greenhouse Gas Emissions in the Construction Sector. Washington,DC: US Environmental Protection Agency; 2009. 12 p.

11. Lindgren M. Evaluation of Factors Influencing Emissions from Tractors and Construction Equipment during Realistic
Work Operations Using Diesel Fuel and Bio-Fuels as Substitute. Biosystems Engineering. 2010 Oct;107(2):123-30.

12. Cole RJ. Energy and Greenhouse Gas Emissions Associated With the Construction of Alternative Structural Systems. Building and Environment. 1999 Mar;23(2):224-37.

13. Lee SE. Shin KS. Kim SW. The Environmental Load Unit Composition and Program Development for LCA of Building: The Construction of Method With LCA for Estimating Environmental Building. Korea Institute of Construction Technology; 2004.

14. Acquaye AA. Input-Output Analysis of Irish Construction Sector Greenhouse Gas Emissions. Building and Environment. 2010 Mar;45(3):784-91.

15. Eggleston S. Buendia L. Miwa K. Ngara T. Tanabe K. ed. 2006 IPOC Guidelines for National Greenhouse Gas Inventories. Hayama (Japan): Institute for Global Environmental Strategies; 2006. p. $2.6-2.14$ 